\section{Prescription Drugs Marketed in the United States Should Be Approved by the FDA}

Two events in the drug regulatory approval process in recent years warrant the attention of managed care pharmacists and should prompt reassessment of assumptions regarding drugs marketed in the United States. The first event, involving levothyroxine, received considerable public attention from 1999 through 2002. The second event involves an appellate court decision in May 1999 regarding combination product esterified estrogen and methyltestosterone (Estratest and Estratest HS, Solvay Pharmaceuticals). The circumstances of these events are noteworthy, and the social and market effects of each are sizable. Levothyroxine products (Synthroid, Levoxyl, Levothroid, Unithroid, and Thyro-Tabs) are the number one drug class in the United States by volume of prescriptions and number of patients. ${ }^{1}$ Estratest and Estratest HS, with combined volume of about 4 million units in community pharmacy in 2002, placed it at approximately rank number 100 among all brand-name drugs by unit volume (utilization). By dollar volume, the levothyroxine products collectively ranked in the top 25 drugs in the United States, with more than $\$ 1.2$ billion in sales, and the Estratest products collectively rank in the top 200 drugs by sales volume. ${ }^{2,3}$

In 2000 and 2001, Abbott Laboratories, which had acquired Knoll Pharmaceuticals and its prescription drug Synthroid, engaged the U.S. Food and Drug Administration in a tug of war over the need for FDA review and approval of Synthroid (levothyroxine). The matter received considerable public attention since Synthroid was the number 3 drug by community pharmacy prescription volume in 2000 and one of the most commonly used drugs in the United States for many years. ${ }^{4}$ Unithroid (Jerome Stevens), formerly marketed as Thyrox, was approved by the FDA on August 21, 2000, as the first levothyroxine product approved through the New Drug Application (NDA) process. The FDA approval of Unithroid commenced a race for FDA approval of competing levothyroxine products by establishing the first "standard" levothyroxine product. At the request of Knoll Pharmaceuticals, the FDA had extended the deadline for levothyroxine approval until August 14, 2001, and said that manufacturers who marketed their drugs "without an approved application after that date would be subject to regulatory action." Any levothyroxine product not approved through an NDA or Abbreviated NDA (ANDA) by August 14, 2001, would be subject to regulation as an unapproved new drug. ${ }^{5}$ Synthroid ultimately received FDA approval near yearend 2002, but not before precipitating a mandate from the FDA to scale down production of Synthroid and alarming physicians, pharmacists, and patients that Synthroid may become unavailable. ${ }^{6}$

A parallel matter involving the combination product, esterified estrogens and methyltestosterone (Estratest and Estratest HS, Solvay Pharmaceuticals), is equally important and instructive. A decision dated May 11, 1999, from the U.S. Court of Appeals, Eleventh Circuit, in Florida Breckenridge v. Solvay
Pharm granted Solvay's abrupt motion to dismiss with prejudice but found that attorneys for both parties engaged in conduct "designed to mislead and confuse the court regarding the regulatory status of Estratest and Menogen." The appellate court judges condemned the conduct of the attorneys and found that "the adversarial parties both had an interest in hiding the fact that they needed FDA approval from the court. In Solvay's case, admitting that Estratest was not legally on the market would be fatal to their claims because the Lanham Act only protects parties engaged in lawful commerce." Since "use in commerce" was defined by the courts as "lawful use in commerce" and since Estratest had never been formally approved by the FDA for marketing in the United States, Solvay had no trademark rights to Estratest and no common-law protection from competition. The judges wrote also, "Breckenridge had an interest in hiding the FDCA [Food, Drug and Cosmetic Act] violations from the court. Since this litigation began, the FDA has taken action against Breckenridge for, among other things, marketing Menogen without FDA approval."

The appellate court judges found in Florida Breckenridge v. Solvay Pharm that the lower court (U.S. District Court for the Southern District of Florida, D.C. Docket No. 97-8417-CIVRYSKAMP) did not specifically address the legal effect of the unapproved sale of Estratest because "the attorneys misled the court into thinking that their clients did not need approval." The appellate court decision included the finding "that there is no magical exception that allows Solvay or Breckenridge to opt out of the FDA approval process. As the government's brief points out, both Estratest and Menogen are 'new drugs' under the FDCA and require approved NDAs or ANDAs before they may be lawfully marketed." Since Estratest was marketed in 1964, 2 years after the 1962 amendments to the FDCA, and Menogen was introduced later (in 1997), neither drug was subject to the grandfather provisions of the FDCA.

This 11th Circuit Court of Appeals decision dissected the purpose of FDA's "DESI" (Drug Efficacy Study Implementation) program, which was to subject drugs already marketed, and therefore found be safe by standards established by the FDA as required by the FDCA of 1938, to a determination of efficacy as required by the 1962 amendments. An independent (DESI) panel reviewed the data regarding efficacy of each drug and made a recommendation to the FDA. If the FDA concurred with the panel recommendation, a notice was published in the Federal Register and a supplemental NDA would be approved for the drug. The DESI program applied only to drugs that already had approved NDAs as of 1962. All other drugs were considered "new" drugs, requiring an approved NDA or ANDA before marketing. The only exception was a drug generally recognized as safe and effective, the "GRASE" exception. The appellate court found that "Estratest cannot satisfy the GRASE exception" because (a) "a drug must meet requirements at least as stringent as those for NDA approval" and (b) "Solvay has continually failed to obtain approval based on the evidence it 
has provided the FDA."

The appellate court in Florida Breckenridge v. Solvay Pharm also chastised the FDA, stating that "It is incomprehensible that Estratest has been allowed on the market without approval for 35 years. It seems reasonable that most patients undergoing treatment for menopause fairly assume that any medication freely available and prescribed by their doctor has been proven safe and effective to the satisfaction of the FDA. They have a right to expect that the laws, as passed by Congress to protect them, are being enforced. To this date, Estratest has failed to satisfy the FDA that it is safe or effective as required by the FDCA, yet the FDA has taken no action to remove the drug from the market. We are accustomed to hearing arguments in situations like this bemoaning scarce governmental resources and the like, but there can be no good excuse for allowing a company to violate the law for 35 years. If the drug is not safe or effective enough to be approved, 35 years seems like sufficient time to get around to taking some action."

We think that the 11th Circuit Court of Appeals in its decision in May 1999 made a reasonable request of the FDA. Four years later, esterified estrogens with methyltestosterone are marketed by Solvay as Estratest HS and Estratest and by Syntho Pharmaceuticals (Farmingdale, NY) as Syntest HS and Syntest DS in equivalent strengths, respectively, ${ }^{8}$ but not interchange-

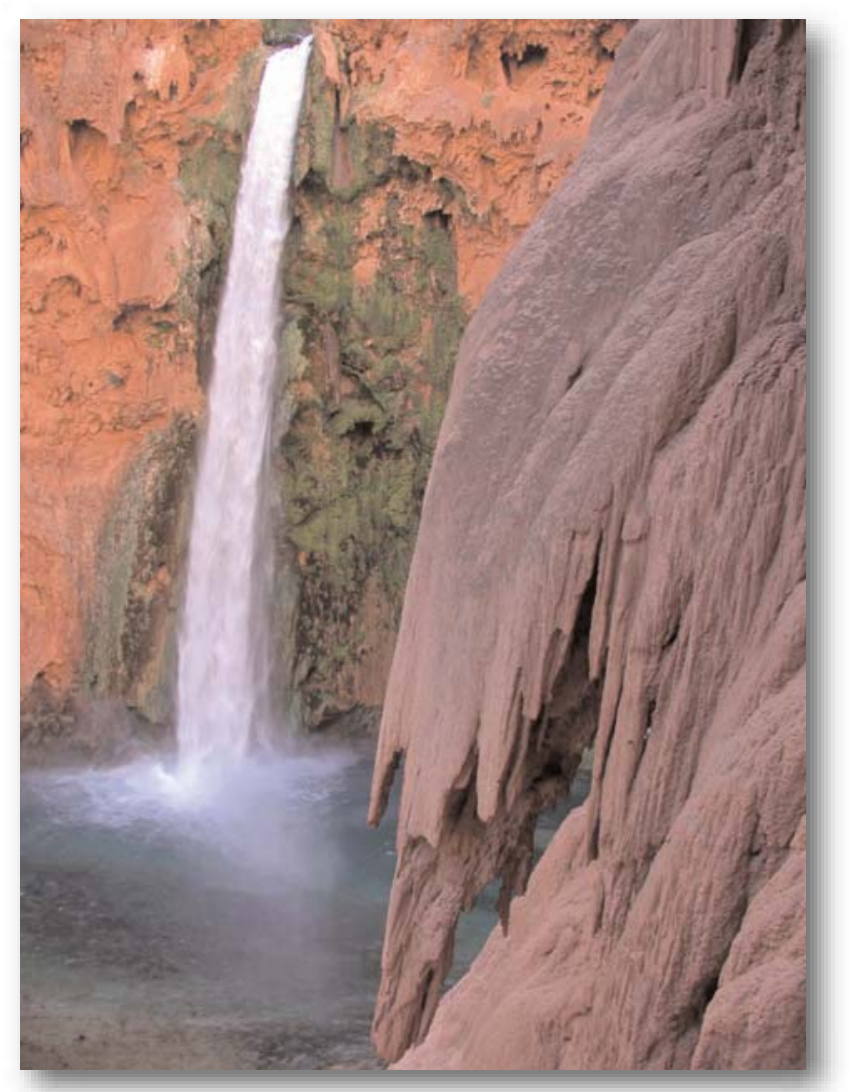

Photograph by John P. Barbuto, MD, Sandy, Utah able since no standard has been established through the NDA process. To add an additional challenge to managed care pharmacists, the drug clearinghouses such as Medispan list Estratest and Estratest HS as brand innovators ("O" drugs) and Syntest HS and Syntest DS as "generic" ("Y") drugs, resulting in brand and generic copayments for members, respectively, in multi-tier copayment drug plans.

Marvin D. Shepherd, PhD, RPh

Director, Center for Pharmacoeconomic Studies

University of Texas at Austin

E-mail: marvshepherd@mail.utexas.edu

Frederic R. Curtiss, PhD, RPh, CEBS

Editor-in-Chief, Journal of Managed Care Pharmacy

E-mail:fcurtiss@amcp.org

\section{REFERENCES}

1. Verispan Scott-Levin Source Prescription Audit (SPA). Top 200 brand-name drugs by units in 2002. Drug Top. March 17, 2003:60.

2. Verispan Scott-Levin Source Prescription Audit (SPA). Top 200 brand drugs by retail dollars in 2002. Drug Top. April 7, 2003:53.

3. Verispan Scott-Levin Source Prescription Audit (SPA). Top 200 brand drugs by retail sales in 2001. Drug Top. February 18, 2002:31.

4. Harris G. Abbott pushes its Synthroid, but should it? Wall Street Journal. July 17, 2002:B1.

5. Jones Stevens Unithroid. Green Sheet. September 4, 2000:4.

6. Adams C, Burton TM. FDA tells Abbott to cut back distribution and prove effectiveness of thyroid drug. Wall Street Journal. July 13, 2001:B6.

7. U.S. 11th Circuit Court of Appeals Reports. Florida Breckenridge v. Solvay Pharm., no. 98-4606; 174 F.3d 1227 (11th Cir. 1999). Available at: www.loislaw.com/pns. Accessed April 1, 2003.

8. Drug Facts and Comparisons. CliniSphere version. St. Louis, MO: Wolters Kluwer Health, Inc.; 2003.

\section{Mooney Falls \\ at Havasupai Canyon in Grand Canyon National Park}

"In a desert may be an oasis. So also in life." 